\title{
Surfactants in the sea-surface microlayer and sub-surface water at estuarine locations: their concentration, distribution, enrichment, and relation to physicochemical characteristics
}

\author{
Yun-Jie Huang ${ }^{\mathrm{a}}$, Peter Brimblecombe ${ }^{\mathrm{b}}$, Chon-Lin Lee ${ }^{\mathrm{a}, \mathrm{c}, \mathrm{d}, \mathrm{e}} *$ and Mohd Talib Latif ${ }^{\mathrm{f}, \mathrm{g}}$ \\ a. Department of Marine Environment and Engineering, National Sun Yat-sen \\ University, 80424 Kaohsiung, Taiwan, ROC \\ b. School of Energy and Environment, City University of Hong Kong, Kowloon, \\ Hong Kong, China \\ c. Department of Public Health, College of Health Sciences, Kaohsiung Medical \\ University, 80424 Kaohsiung, Taiwan, ROC \\ d. Kuroshio Research Group, Asia-Pacific Ocean Research Center, National Sun \\ Yat-sen University, 80424 Kaohsiung, Taiwan, ROC \\ e. Research Center of Environmental Medicine, Kaohsiung Medical University, \\ 80424 Kaohsiung, Taiwan, ROC \\ f. School of Environment and Natural Resource Sciences, Faculty of Science and \\ Technology, Universiti Kebangsaan Malaysia, 43600 Bangi, Selangor, Malaysia \\ g. Institute for Environment and Development (LESTARI), Universiti Kebangsaan \\ Malaysia, 43600 Bangi, Selangor, Malaysia.
}

\begin{abstract}
Samples of sea-surface microlayer (SML) and sub-surface water (SSW) were collected from two areas-Kaohsiung City (Taiwan) and the southwest coast of Peninsular Malaysia to study the influence of SML on enrichment and distribution and to compare SML with the SSW. Anionic surfactants (MBAS) predominated in this study and were significantly higher in Kaohsiung than in Malaysia. Industrial areas in Kaohsiung were enriched with high loads of anthropogenic sources,


accounted for higher surfactant amounts, and pose higher environmental disadvantages than in Malaysia, where pollutants were associated with agricultural activities.

The dissolved organic carbon (DOC), MBAS, and cationic surfactant (DBAS) concentrations in the SML correlated to the SSW, reflecting exchanges between the SML and SSW in Kaohsiung. The relationships between surfactants and the physiochemical parameters indicated that DOC and saltwater dilution might affect the distributions of MBAS and DBAS in Kaohsiung. In Malaysia, DOC might be the important factor controlling DBAS.

* Corresponding author: phone: +886 (7) 5255066; fax: +886 (7) 5255066

Email address: linnohc@mail.nsysu.edu.tw (C-L Lee)

Key word: MBAS, DBAS, DOC, salinity, Kaohsiung harbor, costal environment

\section{Introduction}

The sea-surface microlayer (SML) represents the interface between the ocean and atmosphere, where material transfer is controlled by various physicochemical and biological processes. Its unique characteristics mean that this thin layer is enriched by a complex mixture of substances, including protein, lipids, carbohydrates, and organic surfactants (Stolle et al. 2010). Organic pollutants, such as surfactants, accumulating in the SML can have harmful effects on both natural marine biodiversity and commercial fisheries (Manodori et al. 2006; Zhang et al. 2003).

Surfactants are widely used in numerous detergents, including laundry,
household, and personal cleaning products. These surfactants enter into the
environment through the discharge of sewage effluents (Becagli et al. 2011; Schramm 
et al. 2003; Ying 2006) and can increase the solubility of organic/inorganic matter (e.g., pollutants) in water systems, reduce water quality, and cause eutrophication, thereby endangering planktonic species (Castro et al. 2005; Comber et al. 1993; Razak et al. 2012; Wurl and Obbard 2004; Ying 2006). Recent studies have shown that surfactants are an important subgroup of anthropogenic pollutants in the SML, and might pose a higher threat to the biota in the SML than pollutants in the sub-surface water (SSW) (Latif et al. 2012; Razak et al. 2012; Roslan et al. 2010).

At present, many relevant studies have focused on the environmental effects of surfactants in the form of aerosol particles (Becagli et al. 2011; Hanif 2009; Latif et al. 2011). Much less information is available regarding the distribution and enrichment of surfactants in the SML and SSW, particularly in coastal areas. This study aimed to use methylene blue active substances (MBAS) as markers for anionic surfactants and disulphine blue active substances (DBAS) for cationic surfactants to assess SML and SSW concentrations of surfactants in two different sampling areas: Kaohsiung harbor area in Taiwan and the Straits of Malacca, Malaysia. The relationship between anionic and cationic surfactants and the physicochemical parameters of the aqueous phase was also investigated.

\section{Method}

\subsection{Sampling location}

The SML and SSW samples were collected from 14 stations in the two countries (Taiwan and Malaysia). The sites differed in terms of meteorological conditions and degrees of urbanization (Fig. 1). In Taiwan, the sampling area was Kaohsiung City, a rapidly urbanizing city with many industries. Figure 1a shows the K1-K3 sites, located in the Jhongdou Wetlands Park near the middle of the Love River; this park serves a natural water purification function. The K4 samples were collected directly 
from the Love River. The K5-K10 samples came from sites around Kaohsiung Harbor. These sampling sites receive a variety of discharged contaminants including industrial wastewater, municipal sewage, roadway runoff, and non-point agricultural pollutants.

In Peninsular Malaysia, the four sampling locations were located in Negeri Sembilan and Johor, in the southwest coastal area. The sampling sites were selected based on the presence of nearby activities that might contribute to the SML and SSW (Fig. 1b). The sampling sites M1 and M2 (the Port Dickson site) in Negeri Sembilan were located on the west side of Peninsular Malaysia, and were exposed to anthropogenic sources from tourism, shipping and the oil industry (Fig. 1b). In Johor, the M3 site was located in the Tanjung Piai National Park, an area of mangrove swamps. The M4 station (Pontian) was located in an area of agricultural activities, notably palm oil plantations.

\subsection{Sample collection}

The SML samples were collected using the glass plate technique (Harvey and Burzell 1972) in Kaohsiung and a glass rotation drum, as suggested by Harvery (1966), in Malaysia. These two devices are the most widely used for sampling SML. The thickness of the SML collected by the glass plate method was around 40-60 $\mu \mathrm{m}$ and around $70-100 \mu \mathrm{m}$ for the rotation drum method; these values were similar to the actual SML thickness $50 \pm 10 \mu \mathrm{m}$ reported recently (Falkowska 1999; Zhang et al. 2003). The SML thickness obtained using these two devices indicates that dilution by the water adhering to the sampler is avoided

The SSW samples were collected at a depth of $0.5 \mathrm{~m}$ and stored in brown glass bottles. Both the SML and SSW samples were transported to the laboratory during a single day and stored at $4{ }^{\circ} \mathrm{C}$ prior to surfactant analysis. Both samples (approximately $100 \mathrm{~mL}$ ) were filtered through pre-cleaned $47 \mathrm{~mm}$ filters (Whatman GF/F with $0.7 \mu \mathrm{m}$ 
effective pore size).

Several physicochemical parameters of the SML and SSW samples were characterized: water temperature, $\mathrm{pH}$, salinity, and dissolved organic carbon (DOC). The environmental and hydrographic conditions at each sampling site are described in Table 1. The analysis of chemical parameters was based on the standard methods of National Institute of Environment Analysis: NIEA W217.51A and W424.52A (Taiwan EPA, 2014). The DOC was measured as total carbon by catalytic high temperature oxidation using a total organic carbon analyzer (OI Analytical, Aurora Model 1030W) adapted from Chen et al. (2013).

\subsection{Surfactant analysis}

Surfactant analysis was adapted from a method described previously (Roslan et al. 2010). For anionic surfactants, the filtered sample $(20 \mathrm{~mL})$ was put into a $40 \mathrm{~mL}$ vial and then $2 \mathrm{~mL}$ alkaline buffer, $1 \mathrm{~mL}$ neutral methylene blue solution, and $5 \mathrm{~mL}$ chloroform were added. The vial was closed tightly with a screw-cap and Teflon liner before being vigorously shaken in a vortex mixer for $1 \mathrm{~min}$. Once the two phases were separated, the chloroform layer was transferred by a Pasteur pipette into a new vial containing $22 \mathrm{~mL}$ Milli-Q water (Millipore, Massachusetts, USA; resistance $18 \Omega \mathrm{M}$ $\mathrm{cm}$ or greater) and $1 \mathrm{~mL}$ acid methylene blue solution.

Disulphine blue dye was used to determine cationic surfactants. A $20 \mathrm{~mL}$ volume of sample was put into a $40 \mathrm{~mL}$ vial with $2 \mathrm{~mL}$ acetate buffer and $1 \mathrm{~mL}$ disulphine blue solution, $5 \mathrm{~mL}$ chloroform was added, and the solution was shaken vigorously for 1 min using a vortex mixer.

The absorbance of the chloroform phases containing the MBAS and DBAS were measured with a ultra-violet spectrophotometer set at wavelengths of 650 and $628 \mathrm{~nm}$, respectively. The concentration of MBAS was calculated from a calibration curve 
established with an appropriate anionic surfactant reference material such as sodium dodecyl sulfate (SDS), while the concentration of DBAS was measured using benzyl-dimethyl-tetradecyl-ammonium chloride (BDTAC) dehydrate as a reference.

\subsection{Quality assurance and quality control}

The repeatability and recovery of the analytical procedure was examined for each set of samples. The vials were immersed in hydrochloric acid overnight. Detergents and soaps were avoided during material clean-up to prevent surfactant contamination from the detergents and reduced the likelihood of error in the results. Three replicates were performed for each sample in the surfactant analysis. The extraction efficiencies for MBAS and DBAS were $95.6 \%$ and $95.3 \%$, respectively. The limit of detections calculated based on the standard deviations of the standard solutions and t-values for MBAS and DBAS analyses are $0.05 \mu \mathrm{mol} \mathrm{L}^{-1}$. This value has been used for sample blank for both surfactant determinations. The linear calibration curves for MBAS and DBAS analyses were established between 0.05 to $2.0 \mu \mathrm{mol} \mathrm{L}-1$

\subsection{Statistical Analysis}

Pearson's correlation analyses were performed using all the variables and considered significant at either a $p<0.05$ or $p<0.01$ level of significance. An analysis of variance (ANOVA) test was performed with a 95\% confidence among the concentration from all the sampling sites after the data was found to be in normal distribution.

\section{Results and discussion}

\subsection{Distributions of the surfactants in the SML and SSW}


The average concentrations $(\mathrm{n}=3$ for each sample) of anionic and cationic surfactants, as MBAS and DBAS, in the SML and SSW samples are summarized in Table 1. The average concentrations of MBAS in the SML were recorded as $0.31-0.88 \mu \mathrm{mol} \mathrm{L}^{-1}$ in Kaohsiung and $0.21-0.31 \mu \mathrm{mol} \mathrm{L}^{-1}$ at the Malaysian sampling sites. The average concentration of DBAS surfactants in the SML ranged from $0.11-0.89 \mu \mathrm{mol} \mathrm{L}-1$ at the Kaohsiung sites and $0.18-0.27 \mu \mathrm{mol} \mathrm{L}{ }^{-1}$ in Malaysia. The MBAS concentrations in the SSW ranged from $0.18-0.76 \mu \mathrm{mol} \mathrm{L}^{-1}$ in Kaohsiung and $0.07-0.20 \mu \mathrm{mol} \mathrm{L}^{-1}$ in Malaysia. The DBAS in the SSW ranged from $0.06-0.97 \mu \mathrm{mol}$ $\mathrm{L}^{-1}$ in Kaohsiung and $0.13-0.24 \mu \mathrm{mol} \mathrm{L} \mathrm{L}^{-1}$ in Malaysia.

Comparison of MBAS and DBAS contents in the SML and SSW showed that both surfactant types (MBAS and DBAS) were present at higher levels in the SML than in the SSW $(p<0.05)$. In addition, the average concentrations were higher for MBAS than for DBAS in the SML (Table 1). These results are consistent with previous studies indicating that the dominant surfactant type in the environment was MBAS (Halim et al. 2010; Latif and Brimblecombe 2004; Latif et al. 2012; Roslan et al. 2010).

Statistical analysis suggested that MBAS and DBAS concentrations in the SML were significantly correlated with those in the SSW in Kaohsiung $\left(\mathrm{R}^{2}=0.5531, p<0.01\right.$ in the MBAS; $\mathrm{R}^{2}=0.7973, p<0.01$ in the DBAS) (Fig. 2). This relationship suggested that the concentrations of these two surfactants from the SML were largely affected by their concentrations in the SSW, implying a strong exchange between the SML and SSW at the Kaohsiung sampling sites. The comparatively good hydrodynamic conditions (e.g., turbulent) and frequent water exchange along the Kaohsiung coastal area could enhance homogeneous distribution of the pollutants. These results provide further evidence that occurrence of materials in the SML was directly dependent upon the diffusive supply from the bulk water below. 
In general, the average surfactant concentrations were higher in Kaohsiung than in Malaysia (Table 1); e.g., the MBAS concentrations in the SML and SSW were significantly higher $(p<0.05)$ for Kaohsiung than for Malaysia. The most plausible reason was the different sources of surfactants between Kaohsiung and Malaysia. In Malaysia, sampling sites were located in rural areas, so the sources of surfactants were expected to be mainly generated from agricultural activities around the sampling sites, as well as the activities of microorganisms and biodegradation processes in mangrove swamps (Roslan et al. 2010). Previous studies also suggested that atmospheric surfactants from surrounding anthropogenic sources in Malaysia and from long-range transport might contribute to the surfactant load (Latif et al. 2012; Mustaffa et al. 2014; Roslan et al. 2010). In contrast, the Kaohsiung harbor is a marine environment characterized by anthropogenic contributions due to a high population, traffic, and industrial activities (mainly the petroleum chemical industry and its derivatives). Atmospheric deposition and natural surfactants from phytoplankton excretion and biodegradation of organic substances in the marine environment might also be contributors of a portion of the surfactants in Kaohsiung.

The differences observed in MBAS and DBAS concentrations between Kaohsiung and Malaysia reported in this study (Table 1) were not as large as we expected, as industrial activities in Kaohsiung were much more intensive than Malaysia. This could be caused by recent regulations which might reduce the inputs of anthropogenic surfactants in Kaohsiung City. In addition, vertical water mixing between the SML and SSW and tides could enhance the dispersion of the MBAS and DBAS, which might reduce the surfactant concentrations in Kaohsiung.

Comparison with other studies reveals that the MBAS concentrations in the SML were higher for Kaohsiung (0.31-0.88 $\left.\mu \mathrm{mol} \mathrm{L}^{-1}\right)$ than for Kapas Island and Muar, Malaysia (0.05-0.15 $\left.\mu \mathrm{mol} \mathrm{L}{ }^{-1}\right)$ (Roslan et al. 2010), Lake Chini, Malaysia (0.08-023 
$\mu \mathrm{mol} \mathrm{L}{ }^{-1}$ ) (Latif et al. 2012), the estuarine area of Selangor River, Malaysia (0.14-0.58 $\mu \mathrm{mol} \mathrm{L}{ }^{-1}$ ) (Alsalahi et al., 2013), and Leghorn, Tyrrhenian Sea, Italy (0.13-0.21 $\mu \mathrm{mol}$ $\mathrm{L}^{-1}$ ) (Cincinelli et al. 2001). The concentrations of DBAS in the SML were higher in Kaohsiung (0.11-0.97 $\left.\mu \mathrm{mol} \mathrm{L}{ }^{-1}\right)$ than in Lake Chini, Malaysia $\left(0.09-0.10 \mu \mathrm{mol} \mathrm{L}{ }^{-1}\right)$ (Latif et al. 2012). These differences could reflect the characteristics of the sampling sites. On the other hand, the MBAS and DBAS concentrations in the Malaysian sites examined in this study were similar to those reported by Roslan et al. (2010), probably because the same source was examined; namely the west coast of Peninsular Malaysia. The high concentrations of both surfactant types observed in Kaohsiung resulted from large amounts of commercial surfactant products discharged into the rivers that flowed to the coastal areas. Therefore, the sampling area of Kaohsiung in this study is probably influenced by a large anthropogenic flux from the various industrial and urbanization activities.

The spatial variation observed in this study indicated that the highest concentrations of MBAS and DBAS occurred at the K6 sampling site, located within a marina that housed the Shi-bin ferry (Fig. 1a). These results most likely reflect anthropogenic surfactants from both domestic and industrial effluents, particularly from the dishwashing and laundry activities, as well as organic waste containing high levels of surfactants (Roslan et al. 2010; Scott and Jones 2000; Ying 2006). Some studies indicated that fuel leakage from fishing boats resulted in higher concentrations of anionic surfactants in the surface water (Roslan et al. 2010; Scott and Jones 2000). This was also a reason for the high MBAS concentrations observed at the K6 site. In addition, the high level of DBAS surfactants at the K6 site might arise from untreated domestic runoff containing clothes softeners and hair conditioner residues. An evaluation of the temporal distribution of surfactants showed an increase in DBAS concentrations at K6 during the second survey (2014/02) compared to the first survey 
(2012/03) by as much as four-fold (Table 1). During these two surveys, different weather and tidal conditions, local inputs, and rainfall patterns (Central Weather Bureau, Taiwan, 2015) likely resulted in temporal variations of surfactant concentrations.

The concentrations of surfactants at both the Kaohsiung and the Malaysian sampling sites showed significant correlations between the MBAS and DBAS (Fig. 3), indicating the possibility of identical sources. However, the correlation of determination was higher in Malaysia $\left(\mathrm{R}^{2}=0.6419, p<0.05\right)$ than in Kaohsiung $\left(\mathrm{R}^{2}=0.2513, p<0.05\right)$, indicating a better relationship between the two surfactant types. This result suggested the surfactant source in Malaysia could be attributed to common sources, but the variability in anthropogenic sources and the hydrodynamic conditions (e.g., tides) in Kaohsiung might cause greater uncertainty.

The variability in the MBAS and DBAS observed in different areas and in different studies clearly could reflect differences in nearby inputs, but might also be determined by the meteorological conditions, the SML thickness, diffusion, and turbulent mixing (Chen et al. 2013; Liss and Duce 1997; Wurl et al. 2009). In addition, different methods for sampling SML might contribute to these differences (Guitart et al. 2004). Stolle et al. (2010) found that wind speed is an important factor in changing the SML environment. However, no correlation was found between surfactant concentrations in the SML and SSW and wind speed $(p>0.05)$ in the Kaohsiung area (Table 2), indicating the distribution of surfactants was not directly associated with wind speed. Other factors (e.g., atmospheric sources, hydrodynamic conditions in the water body, etc.) could influence the distribution of surfactants. This needs to be studied further in Kaohsiung.

The concentrations of MBAS and DBAS in Kaohsiung therefore may be related 
to outside inputs from tides and vessels as well as direct inputs from industrial activities. By contrast, in Malaysia, surfactants recorded at the study sites may reflect local discharge and biological activities. Atmospheric deposition may represent another possible input that affects the distribution of surfactants (Hanif et al. 2009; Latif and Brimblecombe 2004; Latif et al. 2011; Latif et al. 2012; Mustaffa et al. 2014; Razak et al. 2012; Roslan et al. 2010), so further investigation of atmospheric surfactant levels may be useful.

\subsection{Relationship with the bulk parameters of water}

The composition of surfactants in the SML and SSW is affected by different types of organic substances, physicochemical properties, biodegradability, and input/output mechanisms for the sampling sites (Alsalahi et al. 2014; Leko et al. 2004; Wurl et al. 2009; Yang 1999). The DOC concentrations in the SML in Kaohsiung were significantly correlated to those in the SSW $\left(\mathrm{R}^{2}=0.4468, p<0.05\right)$, as Chen et al. (2013) observed. The exchange between the SML and SSW therefore affected the distribution of DOC in Kaohsiung. In contrast, no significant correlation was noted between the SML and SSW DOC at the Malaysian sampling sites.

Table 2 shows the correlation between surfactant concentrations and the bulk water parameters in all samples from the Kaohsiung and Malaysian sampling sites. Significant positive correlations were observed between DBAS and DOC in both sampling areas. The DBAS concentrations in this study were therefore influenced by the amount of DOC. In addition, the correlation between DBAS and DOC $(p<0.01)$ was more significant in Kaohsiung than in Malaysia $(\mathrm{p}<0.05)$. A significant correlation also appeared between MBAS and DOC concentrations in the Kaohsiung sampling area, suggesting that DOC might affect the amount of MBAS in Kaohsiung.

The highest DOC concentrations in the SML and SSW were found at the K6 site, 
which also had the highest MBAS and DBAS concentrations.

The DOC concentration was more correlated to surfactants in Kaohsiung than in Malaysia, probably due to the background activities of sampling areas and geographical positions. Discharge water brought a large volume of domestic and natural organic substances into the river in the Kaohsiung region. The anthropogenic sources from industrial activities and urban runoff also would contribute surfactants, rather than natural sources.

Fig. 4 shows that the higher concentrations of DBAS observed in K1-K3 and K6 (second sampling) are associated with lower salinity values and the DBAS concentrations were higher than the MBAS concentrations. In this study, the concentrations of DBAS in Kaohsiung showed an obvious decreasing trend with increasing salinity $\left(\mathrm{R}^{2}=-0.4495, p<0.01\right)$ while MBAS concentrations did not correlated with salinity $(p>0.05)$ (Table 2$)$. The results in this study were similar to the findings in the estuarine area of Selangor River, Malaysia (Alsalahi et al., 2013). These findings in Kaohsiung suggest that the mixing of river water and seawater not only changes the salinity, but also dilutes the DBAS concentration due to the greater amount of saltwater.

\subsection{The enrichment of the SML}

The enrichment factors (EFs) express the degree of enrichment of the SML with respect to the SSW. The SML enrichment may be explained by considering the affinity of surfactants collected at the air-water interface (Garcia-Flor et al. 2005a) expressed as the ratio of the volumetric concentration in the SML relative to the SSW. The EF is defined as follows:

$$
\mathrm{EF}=\mathrm{C}_{\mathrm{M}} / \mathrm{C}_{\mathrm{S}}
$$

where $C_{M}$ is the concentration of any substance in the microlayer and $C_{S}$ is its 
concentration in the sub-surface water.

The EFs of DOC ranged from 0.49-2.22, with four sampling sites (K7, K8, M2 and M3) lower than 1, suggesting that these samples were depleted in DOC relative to the SSW (Table 3). The lower DOC EFs might reflect the different hydrological conditions of the sampling periods in this study, such as rainfall and tidal stage. By contrast, higher MBAS enrichments were found in these four samples. This observation indicated that the increase in MBAS EFs in the SML might be associated with decreasing DOC EFs. The explanation of the relationship between the MBAS EFs and DOC EFs remains unclear. Compared with other SML sampling areas in the world, the average EFs of DOC in this study (1.33) were similar to those reported by Garcia-Flor et al. (2005a) (EF=1.6), Stolle et al. (2010) $(\mathrm{EF}=1.11)$, van Pinxteren et al. (2012) $(\mathrm{EFs}=1.04-1.09)$, Obernosterer et al. (2008) $(\mathrm{EF}=1.01)$ and Carlson (Carlson 1983) $(\mathrm{EFs}=1.16-1.33)$, with small enrichment.

With respect to MBAS and DBAS, the EFs of both surfactants are generally considered indicate enrichment in the SML. In this study, the EFs of MBAS ranged from 0.70-3.00, and three sampling sites (K2, K4 and K9) showed EFs below 1. The EFs of DBAS showed similar values to the cases of MBAS, where the EFs ranged from 0.92-3.50 (Table 3). The highest surfactant EF values were found at M2 for MBAS and at $\mathrm{K} 1$ for DBAS, but the enrichment processes responsible for them remain unknown.

Comparison of the average EFs of MBAS showed Kaohsiung $\left(\mathrm{EF}_{\mathrm{MBAS}}=1.24\right)$ was lower than Malaysia $\left(\mathrm{EF}_{\mathrm{MBAS}}=2.17\right)$. Relatively high $\mathrm{EFs}$ in Malaysian sampling sites could be attributed to several factors, including the concentrations of MBAS in the SSW, the hydrological conditions, and the exchange capacity between the SML and SSW. These factors might reflect the unique characteristic of these surfactants in different sampling areas. Different SML sampling methods might also contribute to 
these differences because of the thickness of the SML and the reproducibility of the sample collections (Garcia-Flor et al. 2005b). Compared with the MBAS in Malaysia, the EFs for DBAS varied from 1.13-1.69 (Table 3), indicating that DBAS was only accumulated to a small extent in the SML.

\section{Conclusion}

This study has provided the first data for MBAS and DBAS measurements in the SML and SSW in Taiwan and a comparison between Kaohsiung and Malaysia. MBAS were the most abundant surfactants observed in this study. Both Kaohsiung and Malaysia showed significant correlations between MBAS and DBAS indicating the sources of these two surfactants for Kaohsiung and Malaysia might be the same. The distributions of MBAS and DBAS in this study may be related to the sources of surfactants in the sampling areas.

The SML surfactants showed a significant positive correlation with their SSW concentrations in Kaohsiung, implying that water exchange was an important factor in controlling the distribution of surfactants. The relatively high MBAS concentrations in Kaohsiung compared with Malaysia suggested that the waters in Kaohsiung were more polluted with surfactants, so potentially more harm was done to the environment than in Malaysia. Both in the SML and SSW, the highest DOC, MBAS, and DBAS concentrations were found at the K6 site. This could be caused by the high wastewater discharge from both domestic and industrial activities. In this study, the variation in DBAS concentrations suggested that meteorological and hydrologic conditions were also factors affecting surfactant distribution in Kaohsiung.

Our data suggest that DOC in the SML was dependent upon the water exchange from the bulk water below in Kaohsiung, which coincides with the conclusions of the correlation of partition of surfactants between the SML and SSW. These relationships 
between the SML and SSW were not found in Malaysia. The limited data set of surfactants and physicochemical parameters in this study precludes a complete assessment of the relationship between the SML and SSW, but correlation results showed that DOC and dilution by seawater possibly affected the distribution of MBAS and DBAS in Kaohsiung. However, surfactant concentrations were only related to the DOC in Malaysia.

A small DOC enrichment in the SML was found except four samples with values less than 1, where high enrichment of MBAS also occurred. In most samples, SML concentrations of these two surfactants were higher than SSW values and the EFs of MBAS were greater in Malaysia than in Kaohsiung. The accumulation was probably due to the sources of local inputs and the hydrological conditions.

The findings in this study indicated that the sources of surfactants and the meteorological and hydrological conditions in the sampling areas can affect the distribution of surfactants. Therefore, future studies should focus on determining the accumulation of surfactants and the increasing solubility effect of organic and inorganic pollutants on marine ecosystems, in order to better understand of the interaction in the SML at the harbor areas. Additionally, research on the seasonal characteristics of the distribution of surfactants in the atmospheric aerosols, SML and SSW in the Kaohsiung harbor may also be useful. To determine detail study on surfactants speciation in the SML and SSW, several other specific techniques should be used for future studies. The use of different type of surfactants such as linear alkyl sulfonate (LAS) as reference materials and determination of detail species of surfactants should also be considered.

\section{Acknowledgements}

We are very thankful to the Ministry of Science and Technology (MOST) and the 
Ministry of Education of Taiwan, for financial support for this research support under Project MOST 102-2611-M-110-009, MOST 100-2611-M-110-010, DOE $01 C 030203$ and DOE 01C030703. This study was also supported partially by Kaohsiung Medical University “Aim for the Top University Grant (Grant No. KMU-TP103A27)".

\section{Reference}

Alsalahi, M. A., Latif, M. T., Ali, M. M., Magam, S. M., Wahid, N. B. A., Khan, M. F., Suratman, S., 2014. Distribution of surfactants along the estuarine area of Selangor River, Malaysia. Mar. Pollut. Bull. 80, 344-350.

Becagli, S., Ghedini, C., Peeters, S., Rottiers, A., Traversi, R., Udisti, R., Chiari, M., Jalba, A., Despiau, S., Dayan, U., Temara, A., 2011. MBAS (Methylene Blue Active Substances) and LAS (Linear Alkylbenzene Sulphonates) in Mediterranean coastal aerosols: Sources and transport processes. Atmos. Environ. 45, 6788-6801.

Carlson, D. J., 1983. Dissolved organic materials in surface microlayers: Temporal and spatial variability and relation to sea stae. Limnol. Oceanogr. 28, 415-431.

Castro, M. J. L., Kovensky, J., Cirelli, A. F., 2005. Ecologically safe alkyl glucoside-based gemini surfactants. Arkivoc, 253-267.

Chen, Y., Yang, G. P., Wu, G. W., Gao, X. C., Xia, Q. Y., 2013. Concentration and characterization of dissolved organic matter in the surface microlayer and subsurface water of the Bohai Sea, China. Cont. Shelf Res. 52, 97-107.

Cincinelli, A., Stortini, A. M., Perugini, M., Checchini, L., Lepri, L., 2001. Organic pollutants in sea-surface microlayer and aerosol in the coastal environment of Leghorn - (Tyrrhenian Sea). Mar. Chem. 76, 77-98.

Comber, M. H. I., Williams, T. D., Stewart, K. M., 1993. The effects of nonylphenol on daphnia-magna. Water Res. 27, 273-276.

Falkowska, L., 1999. sea surface microlayer: a field evaluation of teflon, plate, glass plate and screen sampling techniques. Part 1. Thickness of microlayer samples and relation to wind speed. Oceanologia 41, 211-221.

Garcia-Flor, N., Guitart, C., Abalos, M., Dachs, J., Bayona, J. M., Albaiges, J., 2005 a. Enrichment of organochlorine contaminants in the sea surface microlayer: An organic carbon-driven process. Mar. Chem. 96, 331-345.

Garcia-Flor, N., Guitart, C., Bodineau, L., Dachs, J., Bayona, J. M., Albaiges, J., 2005b. Comparison of sampling devices for the determination of polychlorinated biphenyls in the sea surface microlayer. Mar. Environ. Res. 
$59,255-275$.

Guitart, C., Garcia-Flor, N., Dachs, J., Bayona, J. M., Albaiges, J., 2004. Evaluation of sampling devices for the determination of polycyclic aromatic hydrocarbons in surface microlayer coastal waters. Mar. Pollut. Bull. 48, 961-968.

Halim, N. H. A., Hanif, N. M., Othman, M. R., Latif, M. T., 2010. Colourimetric Determination of Features of an Air Sampling Technique Optimal for Detection of Surfactants. Sains Malays. 39, 175-179.

Hanif, N. M. L., Mohd Talib; Ali, Masni Mohd; Othman, Mohamed Rozali, 2009. Atmospheric Surfactants Around Lake Ecosystems. Euro. J.Sci. Res. 32, 268-276.

Harvey, G. W., 1966. Microlayer Collection from Sea Surface - a New Method and Initial Results. Limnol. Oceanogr. 11, 608-612.

Harvey, G. W., Burzell, L. A., 1972. Simple Microlayer Method for Small Samples. Limnol. Oceanogr. 17, 156-157.

Latif, M. T., Anuwar, N. Y., Srithawirat, T., Razak, I. S., Ramli, N. A., 2011. Composition of Levoglucosan and Surfactants in Atmospheric Aerosols from Biomass Burning. Aerosol Air Qual. Res. 11, 837-845.

Latif, M. T., Brimblecombe, P., 2004. Surfactants in atmospheric aerosols. Environ. Sci. Technol. 38, 6501-6506.

Latif, M. T., Wanfi, L., Hanif, N. M., Roslan, R. N., Ali, M. M., Mushrifah, I., 2012. Composition and distribution of surfactants around Lake Chini, Malaysia. Environ. Monit. Assess. 184, 1325-1334.

Leko, P. O., Kozarac, Z., Cosovic, B., 2004. Surface active substances (SAS) and dissolved organic matter (DOC) in atmospheric precipitation of urban area of Croatia (Zagreb). Water Air Soil Pollut. 158, 295-310.

Lewis, M. A., 1991. Chronic and sublethal toxicities of surfactants to aquatic animals - a review and risk assessment. Water Res. 25, 101-113.

Liss, P. S., Duce, R. A., 1997. The Sea Surface and Global Change, Cambridge University Press, Pages.

Manodori, L., Gambaro, A., Piazza, R., Ferrari, S., Stortini, A. M., Moret, I., Capodaglio, G., 2006. PCBs and PAHs in sea-surface microlayer and sub-surface water samples of the Venice Lagoon (Italy). Mar. Pollut. Bull. 52, 184-192.

Mustaffa, N. I. H., Latif, M. T., Ali, M. M., Khan, M. F., 2014. Source apportionment of surfactants in marine aerosols at different locations along the Malacca Straits. Environ. Sci. Pollut. Res. 21, 6590-6602.

Obernosterer, I., Catala, P., Lami, R., Caparros, J., Ras, J., Bricaud, A., Dupuy, C., 
van Wambeke, F., Lebaron, P., 2008. Biochemical characteristics and bacterial community structure of the sea surface microlayer in the South Pacific Ocean. Biogeosciences 5, 693-705.

Razak, I. S., Tan, Z. Z., Nor, Z. M., Wahid, N. B. A., Mushrifah, I., Latif, M. T., 2012. Correlation Between Surfactants and Heavy Metals in a Natural Lake. Environ. Forensics 14, 59-68.

Roslan, R. N., Hanif, N. M., Othman, M. R., Azmi, W., Yan, X. X., Ali, M. M., Mohamed, C. A. R., Latif, M. T., 2010. Surfactants in the sea-surface microlayer and their contribution to atmospheric aerosols around coastal areas of the Malaysian peninsula. Mar. Pollut. Bull. 60, 1584-1590.

Schramm, L. L., Stasiuk, E. N., Marangoni, D. G., 2003. 2 Surfactants and their applications. Annual Reports Section "C" (Physical Chemistry) 99, 3-48.

Scott, M. J., Jones, M. N., 2000. The biodegradation of surfactants in the environment. Biochimica Et Biophysica Acta-Biomembranes 1508, 235-251.

Stolle, C., Nagel, K., Labrenz, M., Jurgens, K., 2010. Succession of the sea-surface microlayer in the coastal Baltic Sea under natural and experimentally induced low-wind conditions. Biogeosciences 7, 2975-2988.

van Pinxteren, M., Muller, C., Iinuma, Y., Stolle, C., Herrmann, H., 2012. Chemical Characterization of Dissolved Organic Compounds from Coastal Sea Surface Micro layers (Baltic Sea, Germany). Environ. Sci. Technol. 46, 10455-10462.

Wurl, O., Miller, L., Röttgers, R., Vagle, S., 2009. The distribution and fate of surface-active substances in the sea-surface microlayer and water column. Mar. Chem. 115, 1-9.

Wurl, O., Obbard, J. P., 2004. A review of pollutants in the sea-surface microlayer (SML): a unique habitat for marine organisms. Mar. Pollut. Bull. 48, 1016-1030.

Yang, G. P., 1999. Dimethylsulfide enrichment in the surface microlayer of the South China Sea. Mar. Chem. 66, 215-224.

Ying, G. G., 2006. Fate, behavior and effects of surfactants and their degradation products in the environment. Environ Int. 32, 417-31.

Zhang, Z., Liu, L., Liu, C., Cai, W., 2003. Studies on the sea surface microlayer: II. The layer of sudden change of physical and chemical properties. J. Colloid Interf. Sci. 264, 148-159.

\section{Figure captions}

Figure 1. The collection sites for sea-surface microlayer (SML) and sub-surface water (SSW) samples in (a) Kaohsiung City and (b) the Malaysian peninsula. 
Figure 2. Scatter plot showing correlations between the concentrations of anionic (MBAS) and cationic (DBAS) surfactants $\left(\mu \mathrm{mol} \mathrm{L}{ }^{-1}\right)$ in sea-surface microlayer (SML) and sub-surface water (SSW) samples from Kaohsiung

Figure 3. Relationship between the concentrations ( $\left.\mu \mathrm{mol} \mathrm{L}^{-1}\right)$ of anionic (MBAS) and cationic (DBAS) surfactants in samples from Kaohsiung and Malaysia

Figure 4. Concentrations ( $\mu \mathrm{mol} \mathrm{L} \mathrm{L}^{-1}$ ) of anionic (MBAS) and cationic (DBAS) surfactants in (a) sea-surface microlayer (SML) and (b) sub-surface water (SSW) samples at different salinities 
Table 1 Surfactant concentrations and water characteristics of (a) sea-surface microlayer (SML) and (b) sub-surface water (SSW) recorded in Kaohsiung (K) and Malaysia (M)

(a)

\begin{tabular}{cccccccc}
\hline station & date & Water temp $\left({ }^{\circ} \mathrm{C}\right)$ & $\mathrm{pH}$ & Salinity & DOC $\left(\mathrm{mg} \mathrm{L}^{-1}\right)$ & MBAS $\left.(\mu \mathrm{mol} \mathrm{L})^{-1}\right)$ & DBAS $\left(\mu \mathrm{mol} \mathrm{L}^{-1}\right)$ \\
\hline K1 & & 25.8 & 7.76 & 18.1 & 0.90 & $0.55 \pm 0.02$ & $0.56 \pm 0.01$ \\
K2 & $2014 / 02 / 18$ & 27.2 & 7.76 & 21.7 & 2.40 & $0.31 \pm 0.01$ & $0.43 \pm 0.03$ \\
K3 & & 27.8 & 7.85 & 22.9 & 4.45 & $0.59 \pm 0.01$ & $0.79 \pm 0.01$ \\
K4 & \multirow{2}{*}{$2014 / 02 / 27$} & 25.4 & 7.76 & 29.1 & 4.15 & $0.51 \pm 0.01$ & $0.11 \pm 0.01$ \\
K5 & & 27.5 & 8.08 & 32.5 & 3.27 & $0.38 \pm 0.01$ & $0.17 \pm 0.02$ \\
& $2012 / 03 / 29$ & 27.0 & 7.73 & 27.7 & 4.97 & $0.61 \pm 0.04$ & $0.23 \pm 0.01$ \\
K6 & $2014 / 02 / 27$ & 26.5 & 7.84 & 22.1 & 6.61 & $0.88 \pm 0.01$ & $0.89 \pm 0.01$ \\
K7 & $2014 / 04 / 24$ & 31.2 & 8.16 & 30.7 & 2.01 & $0.65 \pm 0.01$ & $0.14 \pm 0.01$ \\
& $2011 / 12 / 12$ & 23.3 & 7.80 & 28.6 & 1.46 & $0.43 \pm 0.01$ & $0.45 \pm 0.01$ \\
K8 & $2012 / 01 / 16$ & 21.6 & 7.86 & 32.9 & 1.84 & $0.40 \pm 0.01$ & $0.28 \pm 0.01$ \\
K9 & & 29.0 & 8.25 & 32.4 & 1.67 & $0.37 \pm 0.02$ & $0.12 \pm 0.01$ \\
K10 & $2014 / 04 / 24$ & 30.3 & 8.26 & 32.6 & 1.48 & $0.50 \pm 0.01$ & $0.11 \pm 0.01$ \\
M1 & & 31.0 & 8.42 & 27.8 & 1.98 & $0.23 \pm 0.02$ & $0.22 \pm 0.03$ \\
M2 & $2012 / 09 / 27$ & 32.1 & 8.20 & 24.7 & 0.98 & $0.21 \pm 0.02$ & $0.19 \pm 0.01$ \\
M3 & & 27.5 & 7.75 & 29.0 & 1.63 & $0.27 \pm 0.03$ & $0.18 \pm 0.01$ \\
M4 & $2012 / 09 / 28$ & 32.6 & 7.88 & 26.8 & 2.08 & $0.31 \pm 0.01$ & $0.27 \pm 0.01$ \\
\hline
\end{tabular}

\begin{tabular}{|c|c|c|c|c|c|c|c|}
\hline \multicolumn{8}{|l|}{ (b) } \\
\hline station & date & Water temp $\left({ }^{\circ} \mathrm{C}\right)$ & $\mathrm{pH}$ & Salinity & $\operatorname{DOC}\left(\mathrm{mg} \mathrm{L}^{-1}\right)$ & MBAS $\left(\mu \mathrm{mol} \mathrm{L}^{-1}\right)$ & DBAS $\left(\mu \mathrm{mol} \mathrm{L}{ }^{-1}\right)$ \\
\hline $\mathrm{K} 1$ & \multirow{3}{*}{$2014 / 02 / 18$} & 25.4 & 7.60 & 20.6 & 0.73 & $0.34 \pm 0.01$ & $0.16 \pm 0.01$ \\
\hline $\mathrm{K} 2$ & & 25.3 & 7.70 & 21.4 & 1.94 & $0.44 \pm 0.02$ & $0.42 \pm 0.02$ \\
\hline K3 & & 27.1 & 7.66 & 22.2 & 3.79 & $0.39 \pm 0.02$ & $0.72 \pm 0.01$ \\
\hline K4 & \multirow{2}{*}{$2014 / 02 / 27$} & 25.1 & 7.67 & 29.8 & 1.99 & $0.55 \pm 0.02$ & $0.09 \pm 0.01$ \\
\hline K5 & & 26.0 & 7.99 & 32.3 & 2.08 & $0.37 \pm 0.01$ & $0.16 \pm 0.02$ \\
\hline \multirow{2}{*}{ K6 } & $2012 / 03 / 29$ & 27.6 & 7.83 & 32.3 & 2.24 & $0.56 \pm 0.04$ & $0.17 \pm 0.00$ \\
\hline & $2014 / 02 / 27$ & 25.2 & 7.74 & 26.0 & 4.44 & $0.76 \pm 0.01$ & $0.97 \pm 0.01$ \\
\hline K7 & $2014 / 04 / 24$ & 30.5 & 8.20 & 32.7 & 4.07 & $0.53 \pm 0.01$ & $0.13 \pm 0.01$ \\
\hline \multirow{2}{*}{ K8 } & $2011 / 12 / 12$ & 24.8 & 7.76 & 29.9 & 0.71 & $0.37 \pm 0.07$ & $0.20 \pm 0.02$ \\
\hline & $2012 / 01 / 16$ & 23.3 & 7.14 & 32.2 & 2.92 & $0.18 \pm 0.03$ & $0.25 \pm 0.01$ \\
\hline K9 & \multirow{2}{*}{$2014 / 04 / 24$} & 30.0 & 8.29 & 33.3 & 1.37 & $0.39 \pm 0.01$ & $0.10 \pm 0.01$ \\
\hline K10 & & 29.1 & 8.34 & 32.6 & 1.38 & $0.39 \pm 0.01$ & $0.06 \pm 0.01$ \\
\hline M1 & \multirow{2}{*}{$2012 / 09 / 27$} & 31.8 & 8.49 & 27.6 & 1.12 & $0.16 \pm 0.02$ & $0.13 \pm 0.00$ \\
\hline M2 & & 33.2 & 8.22 & 24.0 & 1.07 & $0.07 \pm 0.01$ & $0.13 \pm 0.01$ \\
\hline M3 & \multirow{2}{*}{$2012 / 09 / 28$} & 28.0 & 7.63 & 28.7 & 1.65 & $0.10 \pm 0.01$ & $0.14 \pm 0.01$ \\
\hline M4 & & 33.2 & 7.79 & 27.0 & 1.99 & $0.20 \pm 0.01$ & $0.24 \pm 0.01$ \\
\hline
\end{tabular}


Table 2 Correlation coefficients between anionic (MBAS) and cationic (DBAS) surfactant contents and the physicochemical parameters of water from (a) Kaohsiung and (b) Malaysia.

(a)

\begin{tabular}{lccccc}
\hline & salinity & wind speed & DOC & MBAS & DBAS \\
\hline salinity & 1 & & & & \\
wind speed & 0.081 & 1 & & & \\
DOC & -0.179 & -0.118 & 1 & & \\
MBAS & -0.243 & -0.307 & $\mathbf{0 . 5 9 7 * *}$ & 1 & \\
DBAS & $\mathbf{- 0 . 6 7 0 * *}$ & 0.060 & $\mathbf{0 . 5 4 1 * *}$ & $\mathbf{0 . 5 0 1} *$ & 1 \\
\hline
\end{tabular}

(b)

\begin{tabular}{lcccc}
\hline & salinity & DOC & MBAS & DBAS \\
\hline salinity & 1 & & & \\
DOC & 0.547 & 1 & & \\
MBAS & 0.309 & 0.553 & 1 & \\
DBAS & 0.070 & $\mathbf{0 . 7 6 0 *}$ & $\mathbf{0 . 8 0 1 *}$ & 1 \\
\hline
\end{tabular}

* Correlation is significant at the 0.05 level (2-tail)

** Correlation is significant at the 0.01 level (2-tail) 
Table 3 The $\mathrm{EF}^{\mathrm{a}}$ values for anionic surfactants (MBAS), cationic surfactants (DBAS), and dissolved organic carbon (DOC) at different sampling sites.

\begin{tabular}{|c|c|c|c|c|c|c|c|c|c|c|c|c|c|c|c|c|}
\hline & K1 & $\mathrm{K} 2$ & K3 & K4 & K5 & \multicolumn{2}{|c|}{ K6 } & K7 & \multicolumn{2}{|c|}{ K8 } & K9 & K10 & M1 & M2 & M3 & M4 \\
\hline DOC & 1.23 & 1.24 & 1.17 & 2.09 & 1.57 & 2.22 & 1.49 & 0.49 & 2.06 & 0.63 & 1.22 & 1.07 & 1.77 & 0.92 & 0.99 & 1.05 \\
\hline MBAS & 1.62 & 0.70 & 1.51 & 0.93 & 1.03 & 1.09 & 1.16 & 1.23 & 1.16 & 2.22 & 0.95 & 1.28 & 1.44 & 3.00 & 2.70 & 1.55 \\
\hline DBAS & 3.50 & 1.02 & 1.10 & 1.22 & 1.06 & 1.35 & 0.92 & 1.08 & 2.25 & 1.12 & 1.20 & 1.83 & 1.69 & 1.46 & 1.29 & 1.13 \\
\hline
\end{tabular}

a EF is the enrichment factor, defined as the ratio between the SML and SSW volumetric concentrations 


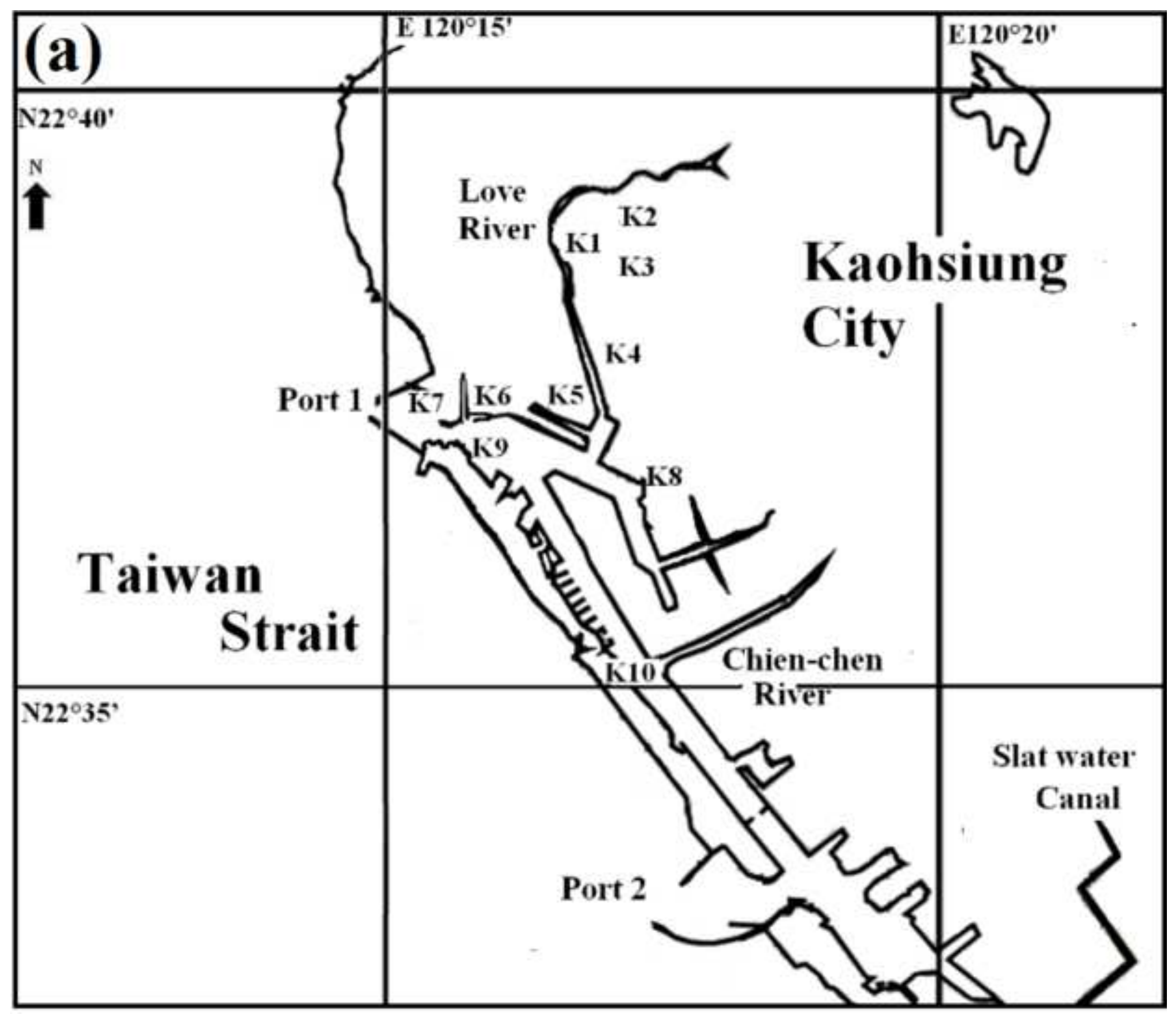




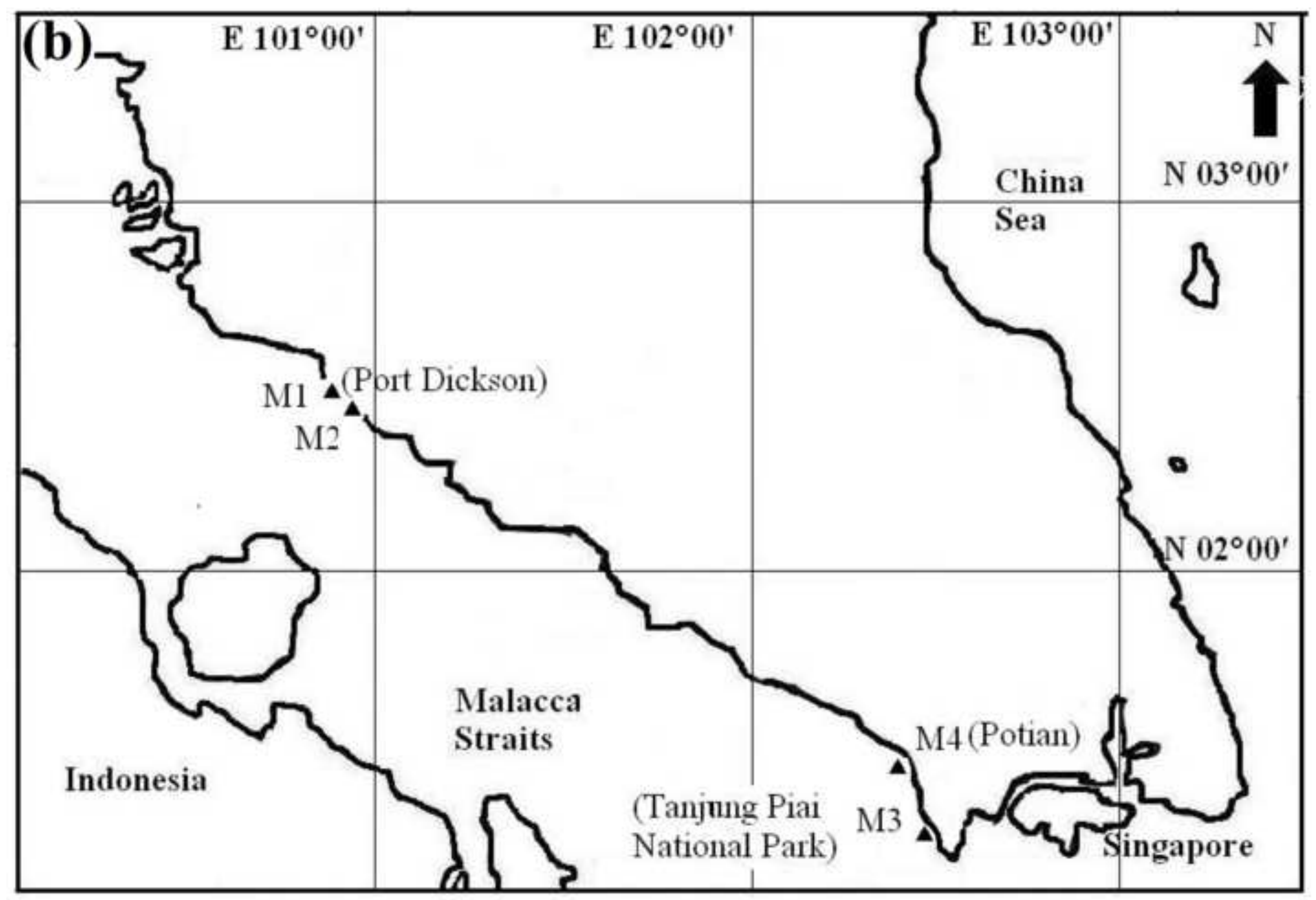




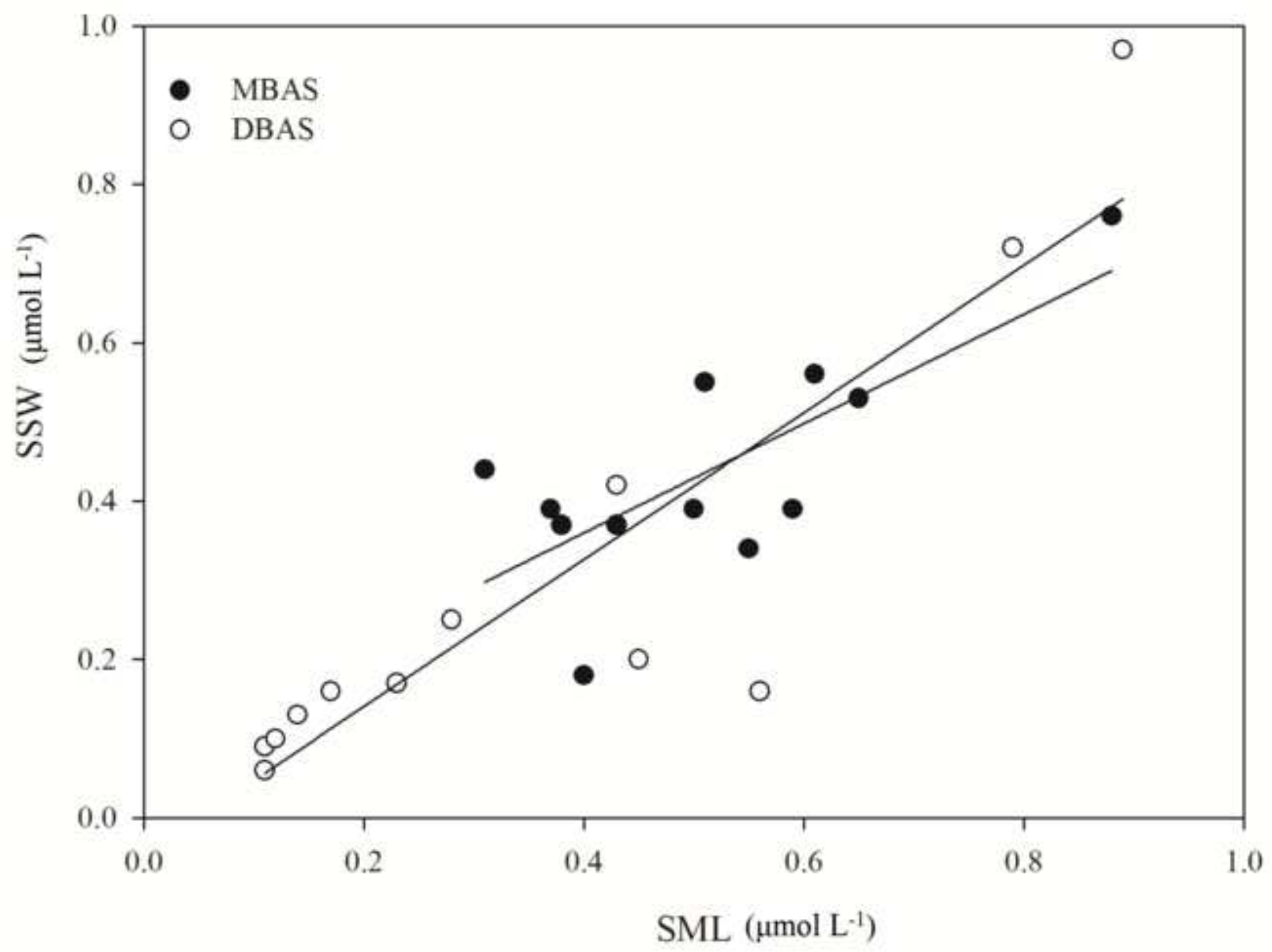




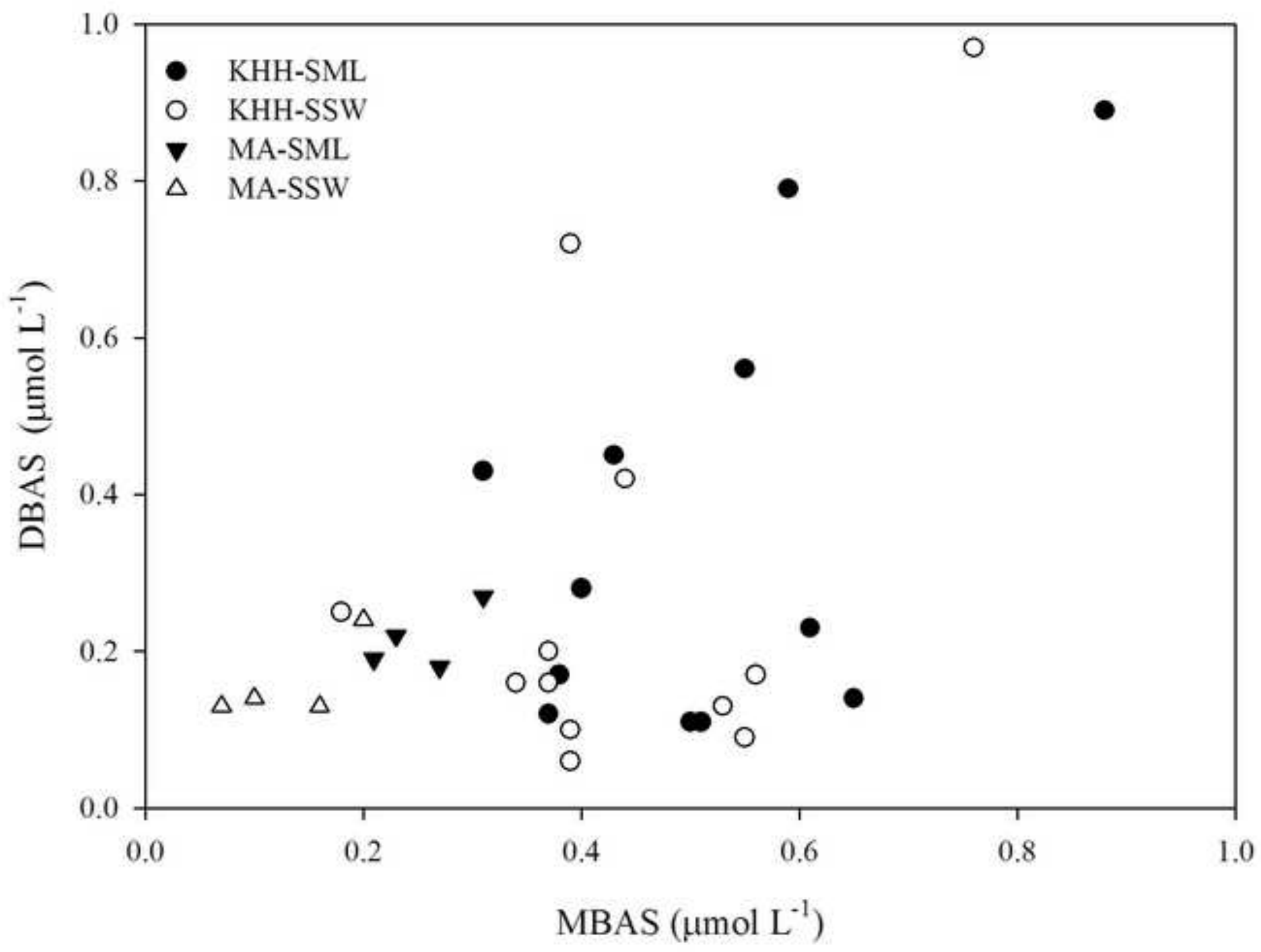


(a)

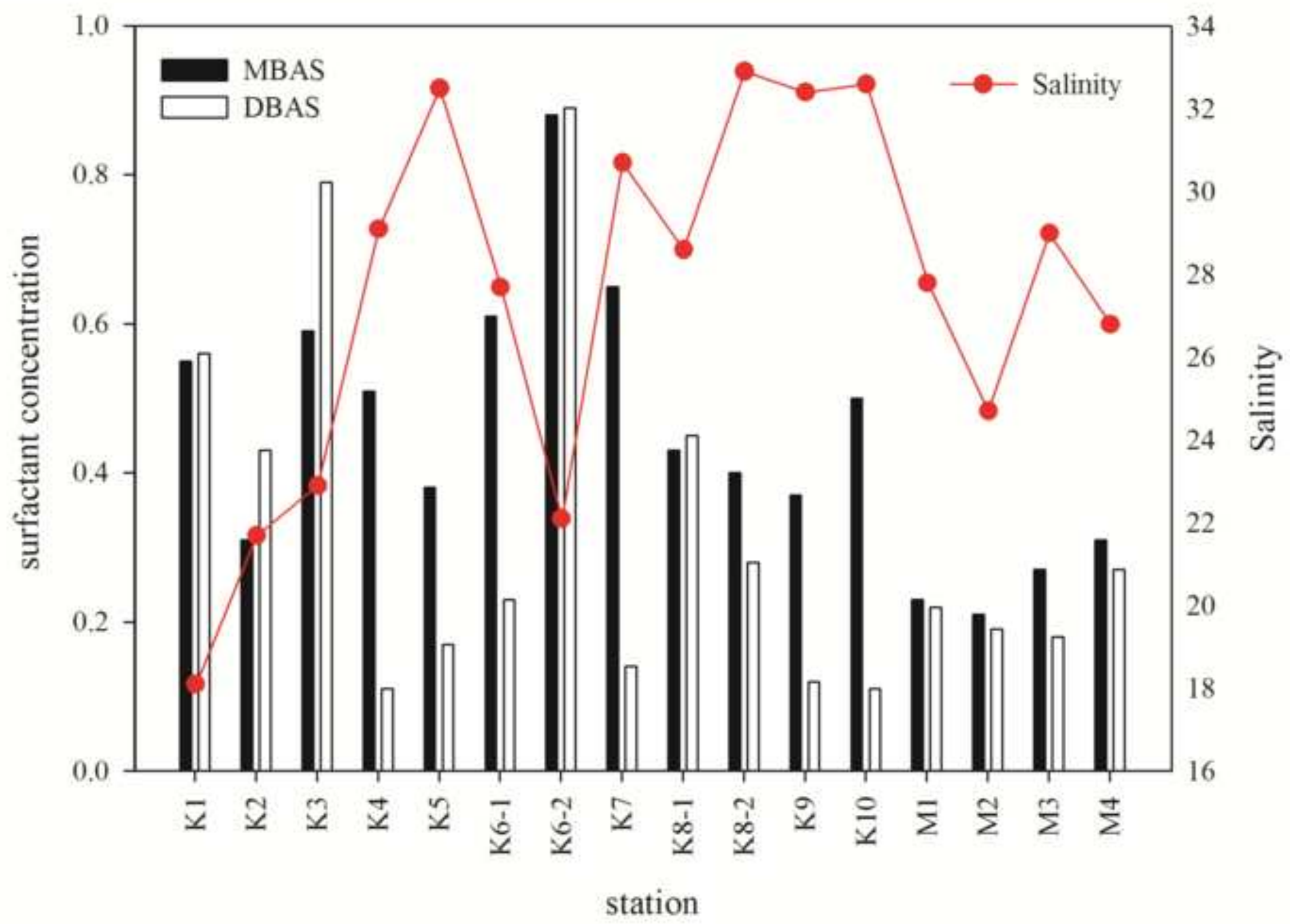


(b)

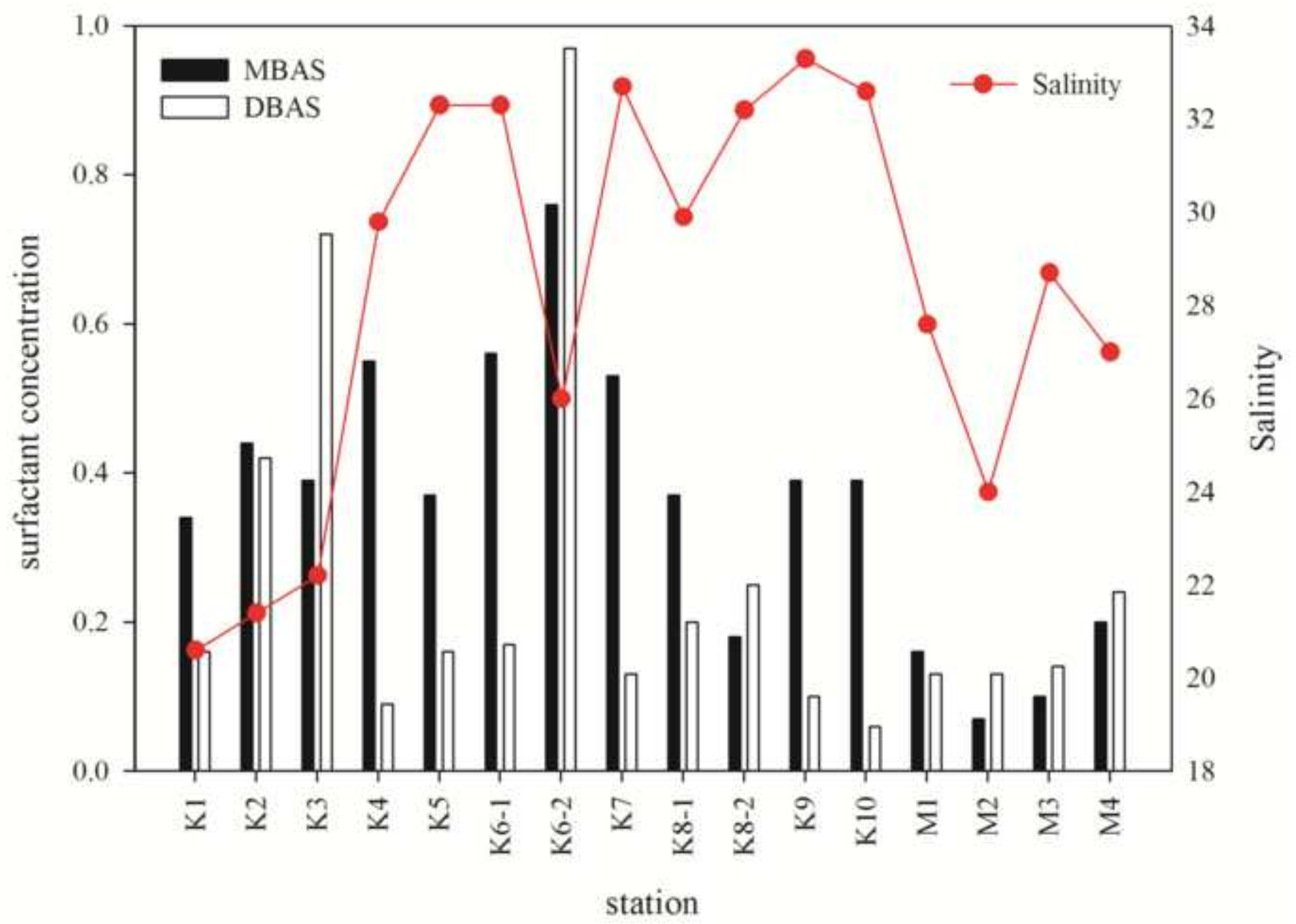

